\title{
Transperitoneal laparoscopic surgery in large adrenal masses
}

\author{
Nuri Alper Sahbaz ${ }^{1}$, Ahmet Cem Dural ${ }^{1}$, Cevher Akarsu' ${ }^{1}$, Deniz Guzey ${ }^{1}$, Mehmet Kulus ${ }^{1}$, Sema Ciftci Dogansen ${ }^{2}$, \\ Meral Mert ${ }^{2}$, Halil Alis ${ }^{3}$ \\ ${ }^{1}$ Department of Surgery, Faculty of Medicine, University of Health Sciences, Bakirkoy Dr. Sadi Konuk Training and Research Hospital, \\ Istanbul, Turkey \\ 2Department of Endocrinology, Faculty of Medicine, University of Health Sciences, Bakirkoy Dr. Sadi Konuk Training and Research \\ Hospital, Istanbul, Turkey \\ ${ }^{3}$ Department of Surgery, Faculty of Medicine, Aydin University, VM Medical Park Florya Hospital, Istanbul, Turkey
}

Videosurgery Miniinv 2020; 15 (1): 106-111 DOI: https://doi.org/10.5114/wiitm.2019.85177

\begin{abstract}
Introduction: The laparoscopic adrenalectomy (LA) has become the gold standard since the transperitoneal laparoscopic approach was first reported.

Aim: To evaluate the applicability, safety and short-term results of laparoscopic surgery in adrenal masses over $6 \mathrm{~cm}$. Material and methods: Demographic data, hormonal activities, imaging modalities, operative findings, operation time, conversion rates, complications, duration of hospital stay and histopathologic results of 128 patients who underwent laparoscopic adrenalectomy were evaluated retrospectively. Patients included in the learning curve $(n=23)$, robotic surgery cases $(n=15)$ and patients with suspected metastasis $(n=4)$ were excluded from the study. Six cm mass size was taken as a reference and two groups were formed (group 1: $<6 \mathrm{~cm}$, group 2: $\geq 6 \mathrm{~cm}$ ). The results of the two groups were compared.

Results: There were 64 cases in group 1 and 22 cases in group 2. Functional mass ratio and mass sides were similar between the groups ( $p=0.30$ and $p=0.17$, respectively). The mean mass size in group 1 was $36.4 \pm 11.2 \mathrm{~mm}$ and in group $282.4 \pm 15.5 \mathrm{~mm}$. The conversion rate was similar between the two groups $(p=0.18)$. The duration of surgery was $135.5 \pm 8.29$ min in group $1,177.0 \pm 14.9$ min in group $2(p=0.014)$. Morbidity and lengths of hospital stay were similar ( $p=0.76, p=0.34$ respectively). Adrenocortical carcinoma was detected in three cases in group 1 , which were completed laparoscopically, and in two cases in group 2, which were converted to open surgery $(p=0.46)$.

Conclusions: Although open surgery is still recommended in the guidelines, studies are now being carried out to ensure that laparoscopy can be safely performed on masses over $6 \mathrm{~cm}$. There was no difference between short-term follow-up and histopathologic results in our study.
\end{abstract}

Key words: large adrenal tumors, adrenalectomy, laparoscopy, minimally invasive adrenalectomy.

\section{Introduction}

The laparoscopic adrenalectomy (LA) has become the gold standard since the transperitoneal laparoscopic approach was first described by Gagner et al. [1-3]. It has been shown to demonstrate benefits in terms of safety, recovery, analgesic requirements and hospital stay when compared to the open procedure $[4,5]$. Beside these benefits, the widespread adoption of Laparoscopic adrenalectomy has also been due to the improvements in laparoscopic equipment and technical expertise [6].

The prevalence of adrenal incidentalomas in imaging modalities performed for different rea-

\section{Address for correspondence}

Nuri Alper Sahbaz, Department of Surgery, Faculty of Medicine, University of Health Sciences, Bakirkoy Dr. Sadi Konuk Training and Research Hospital, Tevfik Sağlam Cad. No. 11, 34147 Istanbul, Turkey, phone: +90 5055572762, e-mail: alpersahbaz@yahoo.com 
sons ranges between $3 \%$ and $5 \%[7,8]$. Laparoscopic adrenalectomy is considered the choice of treatment for benign small adrenal tumors and current guidelines recommend surgical removal of adrenal lesions larger than $4 \mathrm{~cm}$. In contrast, adrenocortical cancer (ACC) is an uncommon malignancy, with an incidence of $0.5-2 / 1$ million population/year. In the lack of local invasion or metastatic disease, the suspicion of ACC is solely based on the size and the imaging features of the lesion [9].

While it has been shown that tumor size is typically an indicator of malignant disease, and it is unclear if the laparoscopic approach to a large and possibly malignant lesion is suitable due to concern over capsular disruption, incomplete resection, and local recurrence [10], it is still debated whether size of the tumor should be a contraindication to the laparoscopic adrenalectomy [11].

Malignancy being the single contraindication for LA [12, 13], the correct surgical approach depends on the ability to differentiate benign and malignant lesions, preoperatively. Without evidence of invasion to surrounding tissues, lymphadenopathy or distant metastasis, malignancy of a large adrenal tumor is difficult to identify before or maybe even during the operation [14].

During the last decade, cut-off values for malignancy potential of adrenal lesions have been increased during the years in various guidelines. The more recent guidelines set this threshold as $6 \mathrm{~cm}$ and reported that lesions greater than $6 \mathrm{~cm}$ have a significant increase in risk for malignancy [15-18]. However, currently, the indication for LA for lesions $>6 \mathrm{~cm}$ is still a matter of debate. Some surgeons regard large tumors as a contraindication [19-21] and some report series with larger adrenal tumors successfully treated laparoscopically [22-24].

\section{Aim}

Our aim was to evaluate the applicability, safety and short-term results of laparoscopic surgery in adrenal masses over $6 \mathrm{~cm}$.

\section{Material and methods}

The records of 128 consecutive patients who underwent laparoscopic adrenalectomy at our institution between December 2012 and December 2017 were evaluated retrospectively. Demographic data, preoperative hormonal activities, imaging modalities, surgical and medical history, operative findings, operation time, conversion to open surgery, complications, duration of hospital stay and histopathologic results were analyzed. Patients included in the learning curve $(n=23)$, robotic surgery cases $(n=15)$ and patients with suspected metastasis $(n=4)$ were excluded from the study to reduce potential sources of bias. Six $\mathrm{cm}$ mass size was taken as a reference and two groups were formed (group 1: $<6 \mathrm{~cm}(n=64)$, group $2: \geq 6 \mathrm{~cm}(n=22))$. The results of the two groups were compared (Figure 1).

All cases were discussed in the multidisciplinary adrenal tumor board for the surgical indication. All procedures were performed by surgeons who have experience in the field of endocrine surgery and minimally invasive surgery as well.

\section{Surgical technique}

Laparoscopic adrenalectomy was performed using the lateral transabdominal approach as described by Gagner et al. [1]. During the procedure we aimed at minimal handling of the tumor and resection with its surrounding fat. Energy devices (LigaSure) were used for the dissection of the tumor but all adrenal veins were clipped before division. Metallic clips (LIGACLIP, Ethicon US, LLC) or Hem-o-lock clips (Teleflex Medical, Research Triangle Park, NC) were used

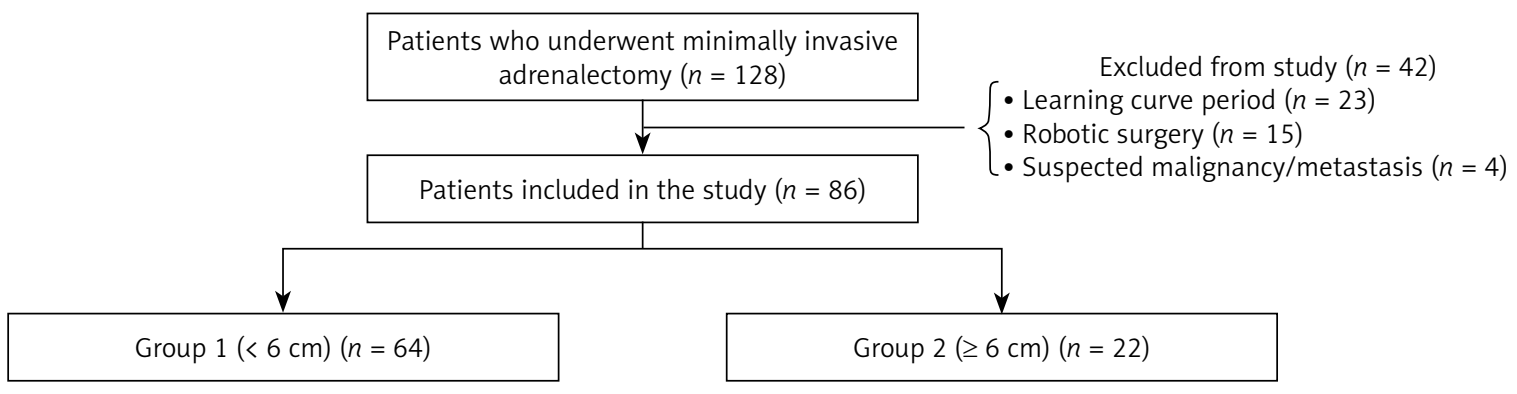

Figure 1. Study flow diagram 


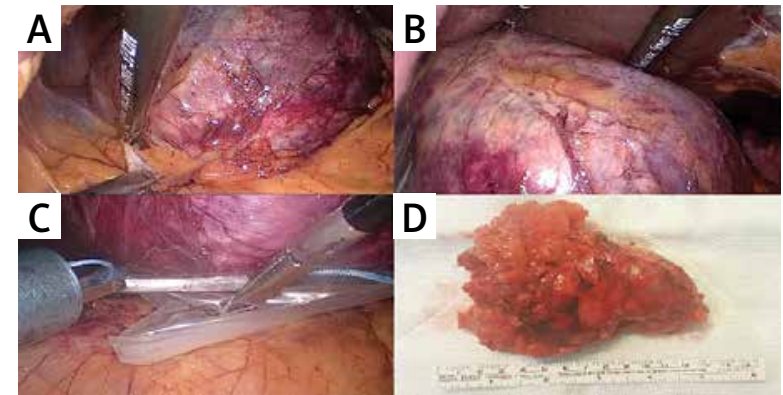

Photo 1. A, B - Dissection and minimal handling of the tumor, $\mathrm{C}$ - removal with endoscopic retrieval bag, $\mathbf{D}$ - resected specimen

for ligation. All tumors were removed using endoscopic retrieval bags. In case of suspicion for a locally invasive tumor, the procedure was converted to open surgery for en-bloc resection \pm lymph node dissection according to oncological principles (Photo 1).

\section{Ethics}

All procedures performed in this study involving human participants were in accordance with the ethical standards of the institutional ethics committee (Registration No: 2015-161-14-11) and with the 1964 Helsinki Declaration and its later amendments or comparable ethical standards. Informed consent was obtained from all individual participants included in the study.

\section{Statistical analysis}

For statistical analysis, a statistical software package (JMP version 10.0.0, SAS, Cary, NC) was used. Continuous variables were expressed as mean $\pm \mathrm{SD}$ or median and interquartile ranges. Categori- cal variables were expressed as frequencies and percentages. Comparison of parametric continuous variables was performed using Student's $t$ test. The Mann-Whitney $U$ test was used for comparison of non-parametric variables. The $\chi^{2}$ test was used in the comparison of categorical variables. $P$-values of 0.05 or less were considered as statistically significant.

\section{Results}

A total of 86 patients were included in the study. Thirty-six of them were hormonally active. Demographic data of the groups are given in Table I. The only difference was a female predominance in group 1 .

The mean operative time was significantly longer in group 2. Average blood loss, conversion rates and intra-operative complication rates did not differ between the two groups. In group 1, 3 patients required conversion to an open approach. The reasons were technical difficulties in dissection in 1 case, adhesions due to previous surgery in the other case and renal vein injury in the last one. In group 2, also 3 patients needed conversion, two of them due to suspicion of malignancy and local invasion and one due to adhesions (Table II).

We encountered one port site hernia in group 1 and one wound infection in group 2 as a post-operative complication. We did not have any mortality. Length of hospital stay was similar in both groups. Post-operative pathology results revealed 3 ACCs in group 1 and 2 ACCs in group $2(p=0.46)$ (Table III).

\section{Discussion}

Adrenalectomies have become more frequent worldwide, especially as minimally invasive tech-

Table I. Demographic data and pre-operative work-up

\begin{tabular}{|lccc|}
\hline Demographics & Group $1(<6 \mathrm{~cm})(n=64)$ & Group 2 $(\geq 6 \mathrm{~cm})(n=22)$ & $P$-value \\
\hline Age, median (IQR) [years] & $53(27-76)$ & $47(19-79)$ & 0.07 \\
\hline Gender, $n(\mathrm{M} / \mathrm{F})$ & $14 / 50$ & $10 / 12$ & 0.03 \\
\hline BMI, mean $\pm \mathrm{SD}\left[\mathrm{kg} / \mathrm{m}^{2}\right]$ & $29.9 \pm 6.8$ & $27.8 \pm 6$ & 0.36 \\
\hline Mass size*, mean \pm SD $[\mathrm{mm}]$ & $36.4 \pm 11.2$ & $82.4 \pm 15.5$ & $<0.001$ \\
\hline Mass side, $n$ (R/L) & $33 / 31$ & $15 / 7$ & 0.17 \\
\hline Hormonal activity, $n$ (non-functioning/functioning) & $38 / 26$ & $12 / 10$ & 0.30 \\
\hline Imaging studies**, $n$ (MRI/other) & $61 / 3$ & $18 / 4$ & 0.06 \\
\hline
\end{tabular}

$I Q R$ - interquantile range, $B M I$ - body mass index, SD - standard deviation, *Mass size on preoperative imaging, MRI-magnetic resonanace imaging, **other - computed tomography, scintigraphy or positron emission tomography. 
Table II. Per-operative findings

\begin{tabular}{|c|c|c|c|}
\hline Pre-operative parameters & Group $1(<6 \mathrm{~cm})(n=64)$ & Group $2(\geq 6 \mathrm{~cm})(n=22)$ & $P$-value \\
\hline Duration of operation, mean \pm SD & $135.5 \pm 66.3$ & $177.1 \pm 69.9$ & 0.01 \\
\hline Estimated blood loss, median (IQR) [ml] & $50(10-300)$ & $80(25-150)$ & 0.23 \\
\hline Conversion to open surgery, $n(\%)$ : & $3 / 4.7$ & $3 / 13.6$ & 0.18 \\
\hline Suspicion of malignancy-local invasion & & 2 & \\
\hline Difficult dissection & 1 & & \\
\hline Adhesion & 1 & 1 & \\
\hline Bleeding due to vascular injury & 1 & & \\
\hline Intra-operative complication, n (\%) & $2 / 3.1$ & $1 / 4.5$ & 0.76 \\
\hline Organ injury (pancreas)* & & 1 & \\
\hline Bleeding due to vascular injury & 1 & & \\
\hline Bleeding due to organ injury (Adrenal itself)* & 1 & & \\
\hline
\end{tabular}

Table III. Post-operative findings

\begin{tabular}{|lccc|}
\hline Post-operative parameters & Group $1(<6 \mathrm{~cm})(n=64)$ & Group $2(\geq 6 \mathrm{~cm})(n=22)$ & $P$-value \\
\hline LOS, median (IQR) & $3(1-9)$ & $3(1-14)$ & 0.07 \\
\hline Rate of ACC, $n(\%)$ & $3(4.7)$ & $2(9)$ & 0.46 \\
\hline \begin{tabular}{l} 
Post-operative complication, $n(\%):$ \\
\hline Port site hernia
\end{tabular} & $1(15)$ & 1 & 0.45 \\
\hline Wound infection & - & - & NA \\
\hline 30-day periooperative mortality & $36.6 \pm 13.5$ & $34.4 \pm 15.4$ & 0.53 \\
\hline Follow-up, mean \pm SD [months] & & & \\
\hline
\end{tabular}

LOS - length of hospital stay, ACC - adrenocortical carcinoma.

niques and surgical skills have improved in the last decades [25]. The size of the tumor, however, has always been a setback for a minimally invasive approach as the risk of malignancy increases with size. During the last decade, cut-off values for malignancy potential of adrenal lesions have been increased during the years in various guidelines. The more recent guidelines set this threshold as $6 \mathrm{~cm}$ and reported that lesions greater than $6 \mathrm{~cm}$ have a significant increase in risk for malignancy. However, many adrenal adenomas are larger than $6 \mathrm{~cm}$. If size is the sole criterion on which the operative approach is based, many patients with benign large adrenal tumors will have an unnecessary open adrenalectomy that might increase their morbidity [26]. However, LA for lesions $>6 \mathrm{~cm}$ is still a matter of debate.
Some surgeons regard large tumors as a contraindication [19-21] and some report series with larger adrenal tumors successfully treated laparoscopically [22-24].

Our study confirmed the applicability and safety of laparoscopic adrenalectomy for large tumors over $6 \mathrm{~cm}$ by comparing operative times, conversion and complication rates, mean blood loss and hospital stay. In our study, we defined the cut-off value for large tumors as $6 \mathrm{~cm}$ and based our measurements on the final histopathological results, since imaging scans tend to underestimate actual size by up to $20 \%$ [27].

Laparoscopic dissection of large adrenal tumors is more demanding due to the limited space to perform an extensive dissection. It may cause increased intra-operative blood loss, conversion rates to open 
approach, mean operative time and longer hospital stay, when compared to small tumors [28]. Tiberio et al. reported in their recent work that longer hospital stays were associated with duration of the operations. In their series, they found that tumor size was not associated with longer operative times or hospital LOS [29]. Pisarska et al. also found in their large series that the size of the tumor did not affect the LOS [30]. In our study mean operation time for lesions $\geq 6 \mathrm{~cm}$ was $177 \mathrm{~min}$, which was significantly longer than for smaller lesions $(p=0.01)$. But this longer duration of operation did not affect the length of hospital stay $(p=0.07)$. In their series of adrenal cysts, Pogorzelski et al. reported using the laparoscopic approach in cysts up to $13 \mathrm{~cm}$ and did not report any problems due to the size of the lesions. They recommend a transperitoneal laparoscopic approach, particularly for cysts larger than $10 \mathrm{~cm}$, as this approach provides a better view of the surgical field [31].

In a large cohort of Castillo et al. $(n=227)$, they determined similar rates of conversions to an open approach and complications between large and small tumors. But they also reported increased operative time, intra-operative blood loss, and hospital LOS with large lesions [32]. Toutounchi et al., in their series, evaluated patients undergoing lateral laparoscopic adrenalectomy with previous abdominal surgery, and reported that the size of the tumor was a reason for conversion [33]. In our series, intraoperative blood loss, rate of conversion and hospital stay were similar between groups $(p=0.23, p=0.18$ and $p=0.07$ respectively). Also, the rate of complications in large tumors was not high as opposed to small masses $(p=0.76)$. In a recent cohort of Feo et al. $(n=200)$ the size of the tumor did not affect the clinical outcome. Likewise, duration of operation, rate of conversion, hospital LOS and complication rates were not affected by tumor size [34].

The inconsistency in the literature could be because of the different definitions used to define tumor size regarding the guidelines, which affect the current endocrine practice $[26,35]$.

Hormonal activity of the lesions and body mass index (BMI) of the patients have also been shown to correlate with the operating time [26]. But contrary to the literature, in our series, hormonal activity $(p=0.30)$ of the tumor or the BMI of the patient $(p=0.36)$ does not seem to affect overall outcome of the patients.
The ACC is a very rare tumor compared to benign adrenal lesions [35]. According to the National Institute of Health $(\mathrm{NIH})$ consensus statement, incidence of ACC is $25 \%$ in lesions larger than $60 \mathrm{~mm}$ [36]. Asari et al. also reported that $81.1 \%$ of tumors larger than $60 \mathrm{~mm}$ in their series were actually benign in the final histopathology [11]. The rate of ACC seen in both groups also did not differ in our series $(p=0.46)$. However, as a limitation, the retrospective nature of our study and low number of patients $(n=22)$ with larger tumors in our series makes interpretation of these data less reliable. Yet, it seems to suggest that tumor size itself should not be a contraindication for laparoscopic adrenalectomy.

\section{Conclusions}

Although open surgery is still recommended in the guidelines, studies are now being carried out to ensure that laparoscopy can be safely performed on masses over $6 \mathrm{~cm}$. The results of this study support the management trends for large adrenal tumors according to recent literature. There was no difference between short-term follow-up and histopathology results in our study. Oncologic principles were not compromised in our study. In the presence of clinical suspicion of local invasion laparoscopy was not insisted on and there was no hesitation over conversion to an open approach.

\section{Conflict of interest}

The authors declare no conflict of interest.

\section{References}

1. Gagner M, Lacroix A, Bolte E. Laparoscopic adrenalectomy in Cushing's syndrome and pheochromocytoma. NEJM 1992; 327: 1033.

2. Smith CD, Weber CJ, Amerson JR. Laparoscopic adrenalectomy: new gold standard. World J Surg 1999; 23: 389-96.

3. Jacobs JK, Goldstein RE, Geer RJ. Laparoscopic adrenalectomy. A new standard of care. Ann Surg 2004; 225: 495-502.

4. Imai T, Kikumori T, Ohiwa M, et al. A case-controlled study of laparoscopic compared with open lateral adrenalectomy. Am J Surg 1999; 178: 50-4.

5. Conzo G, Musella M, Corcione F, et al. Laparoscopic adrenalectomy, a safe procedure for pheochromocytoma. A retrospective review of clinical series. Int J Surg 2013; 11: 152-6.

6. Dalvi AN, Thapar PM, Thapar VB, et al. Laparoscopic adrenalectomy for large tumours: single team experience. J Minim Access Surg 2012; 8: 125-8.

7. Herrera MF, Grant CS, van Heerden JA, et al. Incidentally discovered adrenal tumors: an institutional perspective. Surgery 1991; 110: 1014-21. 
8. Bovio S, Cataldi A, Reimondo G, et al. Prevalence of adrenal incidentaloma in a contemporary computerized tomography series. J Endocrinol Invest 2006; 29: 298-302.

9. Abdel-Aziz TE, Rajeev P, Sadler G, et al. Risk of adrenocortical carcinoma in adrenal tumours greater than $8 \mathrm{~cm}$. World J Surg 2015; 39: 1268-73.

10. Agrusa A, Romano G, Frazzetta G, et al. Laparoscopic adrenalectomy for large adrenal masses: single team experience. Int J Surg 2014; 12 Suppl 1: S72-4.

11. Asari R, Koperek O, Niederle B. Endoscopic adrenalectomy in large adrenal tumors. Surgery 2012; 152: 41-9.

12. Gagner M, Lacroix A, Prinz RA, et al. Early experience with laparoscopic approach for adrenalectomy. Surgery 1993; 114: 1120-4.

13. Gill IS. The case for laparoscopic adrenalectomy. J Urol 2001; 166: 429-36.

14. Boland GW, Dwamena BA, Jagtiani Sangwaiya M, et al. Characterization of adrenal masses by using FDG PET: a systematic review and meta-analysis of diagnostic test performance. Radiology 2010; 259: 117-26.

15. Zeiger M, Thompson G, Duh QY, et al.; American Association of Clinical Endocrinologists and American Association of Endocrine Surgeons Medical Guidelines for the Management of Adrenal Incidentalomas. Endocr Pract 2009; 15 Suppl 1: 1-20.

16. Stefanidis D, Goldfarb M, Kercher KW, et al.; Society of Gastrointestinal and Endoscopic Surgeons. SAGES guidelines for minimally invasive treatment of adrenal pathology. Surg Endosc 2013; 27: 3960-80.

17. Fassnacht M, Arlt W, Bancos I, et al. Management of adrenal incidentalomas: European Society of Endocrinology Clinical Practice Guideline in collaboration with the European Network for the Study of Adrenal Tumors. Eur J Endocrinol 2016; 175: G1-34.

18. National Comprehensive Cancer Network (NCCN). NCCN Clinical Practice Guidelines in Oncology. Neuroendocrine and Adrenal Tumors Version 2.2018. May 4, 2018. Available at: https:// www.nccn.org/professionals/physician_gls/pdf/neuroendocrine.pdf

19. Wells SA, Merke DP, Cutler GB Jr, et al. Therapeutic controversy: the role of laparoscopic surgery in adrenal disease. J Clin Endocrinol Metab 1998; 83: 3041-9.

20. Graham DJ, McHenry CR. The adrenal incidentaloma: guidelines for evaluation and recommendations for management. Surg Oncol Clin North Am 1998; 7: 749-64.

21. Serji B, Souadka A, Benkabbou A, et al. Feasibility and safety of laparoscopic adrenalectomy for large tumours. Arab J Urol 2016; 14: 143-6.

22. Ramacciato G, Mercantini P, La Torre M, et al. Is laparoscopic adrenalectomy safe and effective for adrenal masses larger than $7 \mathrm{~cm}$ ? Surg Endosc 2008; 22: 516-21.

23. Conzo G, Pasquali D, Colantuoni V, et al. Current concepts of pheochromocytoma. Int I Surg 2014; 12: 107-11.

24. Pisano G, Calò PG, Erdas E, et al. Adrenal incidentalomas and subclinical Cushing syndrome: indications to surgery and results in a series of 26 laparoscopic adrenalectomies. Ann Ital Chir 2015; 86: 406-12.

25. Gupta PK, Natarajan B, Pallati PK, et al. Outcomes after laparoscopic adrenalectomy. Surg Endosc 2011; 25: 784-94.
26. Erbil Y, Barbaros U, Karaman G, et al. The change in the principle of performing laparoscopic adrenalectomy from small to large masses. Int I Surg 2009; 7: 266-71.

27. Kouriefs C, Mokbel K, Choy C. Is MRI more accurate than CT in estimating the real size of adrenal tumours? Eur I Surg Oncol 2001; 27: 487-90.

28. Walz MK, Petersenn S, Koch JA, et al. Endoscopic treatment of large primary adrenal tumours. Br J Surg 2005; 92: 719-23.

29. Tiberio GA, Solaini L, Arru L, et al. Factors influencing outcomes in laparoscopic adrenal surgery. Langenbecks Arch Surg 2013; 398: 735-43.

30. Pisarska M, Dworak J, Natkaniec M, et al. Risk factors for prolonged hospitalization in patients undergoing laparoscopic adrenalectomy. Videosurgery Miniinv 2018; 13: 141-7.

31. Pogorzelski R, Toutounchi S, Krajewska E, et al. Adrenal cysts - optimal laparoscopic treatment. Videosurgery Miniinv 2018; 13: 288-91.

32. Castillo OA, Vitagliano G, Secin FP, et al. Laparoscopic adrenalectomy for adrenal masses: does size matter? Urology 2008; 71: 1138-41.

33. Toutounchi S, Pogorzelski R, Legocka ME, et al. Lateral laparoscopic adrenalectomy in patients with previous abdominal surgery - single-center experience. Videosurgery Miniinv 2018; 13: 283-7.

34. Feo CV, Portinari M, Maestroni U, et al. Applicability of laparoscopic approach to the resection of large adrenal tumors: a retrospective cohort study on 200 patients. Surg Endosc 2016; 30: 3532-40.

35. MacGillivray DC, Whalen GF, Malchoff CD, et al. Laparoscopic resection of large adrenal tumors. Ann Surg Oncol 2002; 9: 480-5.

36. NIH state-of-the-science statement on management of the clinically inapparent adrenal mass ("incidentaloma"). NIH Consens State Sci Statements 2002; 19: 1-25.

Received: 5.03.2019, accepted: 19.04.2019. 